\title{
Access to Affordable Daycare and Women's Economic Opportunities: Evidence from a Cluster-Randomized Intervention in India
}

\author{
Authors: \\ Arijit Nandi, ${ }^{*}$ arijit.nandi@mcgill.ca \\ Parul Agarwal, ${ }^{2}$ parul.agarwal@,ifmr.ac.in \\ Anoushaka Chandrashekar, ${ }^{2}$ anoushaka.chandrashekar@ifmr.ac.in \\ Sam Harper, ${ }^{1}$ sam.harper@mcgill.ca \\ ${ }^{1}$ Institute for Health and Social Policy \& Department of Epidemiology, Biostatistics \& \\ Occupational Health, McGill University; Montreal, Quebec CANADA \\ ${ }^{2}$ Institute for Financial Management and Research-Leveraging Evidence for Access and \\ Development (IFMR-LEAD); Chennai, Tamil Nadu INDIA
}

\author{
*Correspondence: \\ Arijit Nandi \\ Institute for Health and Social Policy \& Department of Epidemiology \\ McGill University \\ 1130 Pine Avenue West \\ Montreal, QC H3A 1A3 CANADA \\ 514.398.7849 | arijit.nandi@mcgill.ca
}

This is an Accepted Manuscript of an article published by Taylor \& Francis in Journal of Development Effectiveness on 2020-08-13, available online:

https://www.tandfonline.com/doi/full/10.1080/19439342.2020.1773898. 


\begin{abstract}
We used data from a cluster-randomized trial in rural Rajasthan, India to evaluate the impact of providing access to a community-based daycare program on women's economic outcomes two years later. The sample included 2858 mothers with age-eligible children. Providing access to daycare led $43 \%$ of households to utilize them. The intervention reduced time on childcare by 16.0 minutes/day $(95 \% \mathrm{CI}=-10.6,42.5)$ and increased the probabilities that women were paid in cash and spent time during the prior day on paid work by $2.3(95 \% \mathrm{CI}=0.0,4.5)$ and $2.6(95 \% \mathrm{CI}=0.9$, 4.4) percentage points. Other indicators of labor force participation and income were unaffected.
\end{abstract}

\title{
KEYWORDS
}

India, daycare, time use, employment, economic opportunity, cluster-randomized trial 


\section{INTRODUCTION}

\section{Objectives and study context}

There is a lack of credible research for constructing evidence-based policies for improving access to daycare in India in ways that benefit health and socioeconomic well-being, particularly for women and young children. This paper presents the initial findings from a cluster-randomized trial, named the Uttam Unnati ("great progress") study, which aims to address this research gap. The overarching objective of the study is to evaluate the effect of providing access to an affordable, community-based daycare program, operated by the non-governmental development organization Seva Mandir, on health, socioeconomic well-being, and empowerment among women living in rural Rajasthan, India.

This study takes place in the Udaipur district of Rajasthan, India. Relative to other Indian states, Rajasthan performs poorly in terms of gender equality in educational and economic outcomes. Based on the Indian National Family Health Survey (NFHS), the sex ratio (girls per 1000 boys) of children aged 6-17 years who attended school in Rajasthan was 745 in 2005-6. Furthermore, only 11.3 percent of women in Rajasthan ages $20-49$ years had 10 or more years of education. These figures ranked Rajasthan lowest among all states.(Kishor and Gupta 2009) Data from the most recent NFHS, conducted in 2015-6, show that only one-half of women in the Udaipur district were literate, compared to $84.3 \%$ of men. Among women between 20 and 24 years of age, $40.4 \%$ were married before age 18 years.

In this analysis we examined the effects of providing access to daycare on the uptake of daycare, women's time spent on childcare, labor force participation, and household income, measured 
roughly two years after the intervention. Given the lack of affordable and reliable alternatives, we hypothesized that there would be substantial enrollment in the daycare program, although prior research suggests there may be cultural barriers to leaving children at a formal daycare center. Based on prior literature suggesting that access to daycare increases women's labor force attachment (Attanasio and Vera-Hernandez 2004; Berlinski, Galiani, and Gertler 2009; Barros et al. 2013; Berlinski, Galiani, and McEwan 2011; Angeles et al. 2014) and income,(Deutsch 1998; Nakahara et al. 2010) we hypothesized that women living in treated areas would be more likely to engage in non-domestic work after the intervention.

\section{Background}

India ranks among the lowest in the world in terms of women's economic participation. Despite experiencing high average annual GDP growth, women's labor force participation rates in India slid from 37 percent to 27 percent between 2004-5 and 2011-2, largely because rural women were dropping out of the work force,(Chaudhary and Verick 2014) and more recent data suggest that this downward trend has continued.(Verick 2018) According to the World Economic Forum's 2016 Global Gender Gap Report, India ranked 136th out of 144 countries in terms of women's economic participation and opportunity.(World Economic Forum. The global gender gap report 2016 2016) The 2015 Power of Parity report published by McKinsey and Co. suggests that India has the greatest potential for additional GDP growth from advancing women's equality.(Woetzel et al. 2015) Multiple socio-demographic, cultural, and structural factors might influence trends in women's labor force participation and empowerment in India, including patriarchal social norms that restrict women's educational and economic achievement, limited employment opportunities, 
and inadequate access to services to alleviate the dual demands of domestic duties and unpaid care work.(Sorsa et al. 2015; Kapsos, Silbermann, and Bourmpoula 2014)

Familial rather than institutional care has been the dominant mode of childcare for pre-primary school aged children in India, with most responsibilities for child-rearing falling on women.(Palriwala and Neetha 2011) Few rural women are employed outside of the household and, among those who are, most are engaged in informal or casual employment, oftentimes in the agricultural sector;(Paul and Raju 2014; Srivastava and Srivastava 2010) the concentration of women in the informal economy has consigned them to the role of childcare provider. The lack of a cohesive and reliable system of public crèches or other childcare programs may have reinforced this pattern.

Recent government efforts, including expanded financial assistance for crèches in 2005-2006 under the auspices of the Rajiv Gandhi National Crèche Scheme (RGNCS), remain inadequate. For example, a 2013 report on the performance of the RGNCS indicated that only about 800,000 children were receiving benefits through the program in 2008-9; the report concluded the program fell short of the target of providing quality daycare services.("Performance of the Rajiv Gandhi National Crèche Scheme for Children of Working Mothers" 2013) A parallel program, the Integrated Child Development Scheme (ICDS) provides meals to children through local institutions called "anganwadis", and expansion of the ICDS to provide childcare services has been proposed.("Steering Committee on Women's Agency and Child Rights. Twelfth Five Year Plan (2012-2017)" 2011) However, several studies suggests the anganwadi program provides poor coverage and is marked by insufficient hours of operation, poorly trained workers, chronic staff 
absenteeism, and substandard facilities.(Sahoo et al. 2016; Malik et al. 2015; Chudasama et al. 2016; Palriwala and Neetha 2011) Thus, this program would likely require a substantial investment to provide an accessible and high-quality alternative to family care.

Inadequate daycare services might contribute to gender inequality over the life-course by restricting women's educational and economic opportunities. With few alternatives, Indian women are often relegated to unpaid domestic work, including childcare.(Palriwala and Neetha 2011) Time use surveys suggest women spend nearly 6 hours a day in unpaid domestic work, compared to roughly one hour for men.(Palriwala and Neetha 2011) Importantly, women retain responsibilities for unpaid domestic work even if they take up employment, usually in the informal economy, producing conflicting demands on their time. Women in the labour force are often forced to bring children to work, leave them home unattended, or entrust their care to older siblings.(Palriwala and Neetha 2011) The constant juggling of these arrangements may also increase the cognitive load on women in ways that impair decision-making.(Mullainathan and Shafir 2013) The demand of caring for younger siblings is a key explanation for why girls, on average, have higher rates of truancy, illiteracy, and dropout than boys, and may contribute to gender gaps in educational achievement.(Wu et al. 2007; Sundaram and Vanneman 2008; PROBE Team (India) and Delhi School of Economics. Centre for Development Economics. 1999; De and PROBE Team (India) 2011) This reduces the economic opportunities available to women directly by limiting their educational achievement and literacy,(Sharma, Sharma, and Nagar 2007) and indirectly by hastening marriage and the time to first childbirth.(Chatterjee 2011) 
The provision of affordable and reliable daycare services is a potentially important policy lever for reducing gender inequality, improving health and socioeconomic well-being, and empowering women. For mothers, access to daycare might reduce barriers to labor force entry and generate new economic opportunities, which is one of the building blocks for empowerment (Kabeer, Mahmud, and Tasneem 2011). Additionally, access to daycare might improve women's mental health. For example, women often report that they perform domestic duties out of compulsion rather than choice (Kabeer 2012). Access to daycare could alleviate "time poverty", lower stress levels, and improve mental health and subjective well-being by reducing the conflicting demands on women's time and increasing women's autonomy. The provision of daycare might also benefit children and adolescents by removing the responsibility of caring for younger children, which limits educational opportunities. Under-nutrition and illiteracy remain challenges in many lowand middle-income countries (LMICs), especially India (Subramanian and Smith 2006), and daycare programs could also improve children's health and development outcomes through the provision of meals and learning programs. A conceptual model illustrating the potential links between lack of affordable and reliable daycare services and women's diminished empowerment is show in Supplementary Figure 1.

Among high income countries there is evidence that access to formal, center-based childcare increases maternal labor force participation.(Brown et al. 2014) However, there are reasons to suspect that the evidence from high-income countries may not be directly transportable to LMICs, largely because of important differences in the quality and structure of daycare programs, the availability of work opportunities, household dynamics, and time constraints in low-resource environments. Evidence from LMICs concerning the impact of daycare provision on women is 
limited. A recent systematic review of the literature on daycare and mothers' social, economic, and health outcomes in LMICs found only one randomized and a handful of observational studies of the impact of formal daycare on maternal labor force participation. Across 9 studies, a 30 percentage point increase in daycare increased maternal employment by 6 percentage points, but there was considerable heterogeneity among studies.(Harper, Austin, and Nandi 2017) The review highlighted the limitations of the extant literature. Existing evaluation studies simply compare outcomes between those who utilize daycare and those who do not. However, the self-selection of individuals into daycare programs (e.g., healthier or wealthier mothers may be more likely to use daycare) makes it impossible to know whether it is daycare or other factors that led to improved outcomes. With respect to external validity, extant work is derived almost entirely from Latin American countries and may not be generalizable to other regions, including South Asia.

\section{MATERIALS AND METHODS}

\section{Study design and sample}

This study utilizes the baseline and endline waves of data of a cluster-randomized trial which concluded in 2018. The sample was derived from 160 village hamlets from five blocks in the Udaipur district (Badgaon, Girwa, Jhadol, Kherwara, Kotra) where Seva Mandir had not previously established daycares, known as balwadis (Supplementary Figure 2). In coordination with Seva Mandir, we selected eligible hamlets that satisfied five criteria determined a priori, specifically: (1) minimum distance of at least 1.5 kilometers between study hamlets, as well as between a study hamlet and an existing anganwadi or balwadi, to reduce the potential for contamination effects (i.e., spillovers, specifically children from control villages attending daycares in treated villages); (2) a minimum number of children ( $\geq 25)$ in the appropriate age range 
in the hamlet to ensure adequate demand; (3) an existing structure suitable for a daycare; (4) a qualified woman, living in the study hamlet or nearby, to operate the daycare; and (5) adequate demand from the village council (Village Development Committee of Seva Mandir) for a new daycare. These are the criteria that Seva Mandir uses to establish a balwadi.

In late 2014 we completed a household census in village hamlets in the Udaipur district in Rajasthan, India to confirm the eligibility of the hamlet, enumerate the population, and identify potential households for inclusion. Eligible households were those that included at least one mother, either biological or guardian, of a daycare eligible child between one and six years of age. We randomly selected one woman meeting these criteria from each eligible household, resulting in 3899 potential respondents. The census was followed by a baseline survey in early 2015 . At this stage, 343 women were deemed ineligible during the baseline survey. Among the remaining 3556 women, 95 migrated and could not be contacted, 127 could not be contacted after three attempts, 5 refused participation, and 152 did not respond for other reasons, resulting in a baseline sample of 3177 mothers (participation rate $=89 \%$ ) with a child between one and six years of age (Figure 1).

In the fall of 2015, Seva Mandir offered to establish a balwadi in 80 randomly selected hamlets, as described below. The remaining 80 hamlets served as control groups that were ineligible to receive a balwadi until after February 2018. The first post-intervention follow-up survey of baseline participants was conducted in mid to late 2016 among 3042 respondents, which was followed by a final endline survey approximately one year later in late 2017 among 2858 of 3177 
baseline respondents (follow-up rate $=90.0 \%$ ). Further details on the study design, sampling, and survey procedures are available elsewhere.(Nandi et al. 2016)

We obtained informed consent in written form if participants could read and write, and orally from those who could not. At the completion of each interview, respondents were given an in-kind compensation for their time, valued at 100 Indian rupees (INR), or 1.56 US Dollars (USD) based on an average annual exchange rate of 64.11 INR to 1 USD in 2015. The Institutional Review Board of McGill University's Faculty of Medicine and the Human Subjects Committee of the Institute for Financial Management and Research in Chennai, India approved this study.

\section{Randomization}

Because daycare programs are made available to the entire community it was not feasible to randomize at the level of individual families. Instead, we randomized at the level of the village hamlet, which are small settlements that surround a village center, but constitute independent units. Based on focus group data and prior knowledge of heterogeneity in the Udaipur district, we chose to stratify by block group (an administrative unit) to prevent variations in the distributions of blocks across treatment groups (e.g., if women in treated hamlets were more likely to reside in blocks with more economic opportunities). Because four of the five blocks contained an odd number of hamlets, the randomization was done so that two of the four blocks would have an additional treated hamlet and the remaining two would have an additional control hamlet. Due to the nature of the intervention it was not possible to blind study personnel or participants after the implementation of the intervention. However, we concealed the allocation of hamlets to treatment 
or control status until after the baseline survey in order to minimize opportunities for bias in recruitment of participants and the baseline survey.

\section{Intervention}

The intervention is the randomized introduction of full time daycare centers in areas where they were not yet available. The balwadis are community-based daycares implemented by Seva Mandir, which operates daycare programs in other areas in the Udaipur district. Each of the balwadis provides childcare, nutritious food and supplements, basic medicines, and preschool education to children one to six years old. The balwadi program also aims to increase immunization coverage of children by maintaining immunization records and following-up with parents and government nurses. Balwadis are operated by local women, called sanchalikas, who are hired and trained by Seva Mandir. Sanchalikas receive approximately 20 days of training each year regarding their roles and responsibilities. The sanchalikas meet with children's families on a quarterly basis to discuss their child's progress. Balwadis were established in 77 of the 80 village hamlets randomized to the treatment group.

\section{Measures}

\section{Outcomes}

We measured eight participant-level outcomes that could plausibly be affected by access to affordable daycare within the study period. First, we created an indicator for whether the respondent made any use of a Seva Mandir operated balwadi in the roughly two year follow-up period, based on questions from the midline and endline surveys that asked respondents about where each of their children spend most of their day and whether each child has attended a Seva 
Mandir operated balwadi at any time in the past year. Second, we measured several primary outcomes related to women's employment and household income. Women were asked about any work in the past seven days, including jobs for which they were paid in cash or kind, as well as work on the family farm or in the family business. For respondents who worked in the past 12 months, we asked whether they worked for a family member, for someone else, for the government, or were self-employed; the response categories for "family member", "someone else", and "government" were combined and served as the referent for "self-employed". Women who reported working in the past 12 months were also if they were paid in cash for their work and if the work was year round vs. seasonal or once in a while. Respondents reported the household income received in the past 12 months from various categories (e.g., agricultural income, business income, rents, remittances, government payments), and these responses were summed to measure total household income. Household income was truncated at the $99^{\text {th }}$ percentile to address outlying values.

As a secondary outcome, women's use of time in the past day was measured using a structured questionnaire, adapted from (Beaman et al. 2012), that asked respondents whether they spent any time in the past 24 hours on specific activities (e.g., gathering fuel or firewood, collecting water, caring for younger children), how much time they spent on each activity, and whether this amount reflected the usual amount of time spent on the activity. In order to measure whether women were simultaneously engaged in childcare while performing other primary activities (multitasking), for each activity we asked if the respondent was simultaneously taking care of children. For these analyses we looked specifically at total time in minutes spent on childcare, which represents the sum of direct time spent caring for younger children and indirect time taking care of children while 
performing other activities. We also measured whether women had spent any time on paid work (binary), which was based on whether they reported any time in the past 24 hours working as an agricultural laborer, as a non-agricultural laborer, or doing any other work for pay.

\section{Covariates}

Covariates included the baseline values of the primary outcomes described above, with the exceptions of mother's balwadi use, which was not applicable at baseline, and time spent on childcare, which included minutes spent on direct care only since indirect time spent on childcare while performing other activities was not collected at baseline. We also included block as a covariate because it was used to stratify the randomization. Given the heterogeneity across blocks in sociodemographic characteristics and local economic conditions, we estimated the impact of the intervention separately in each of the five blocks. Additionally, because several past studies suggested that the impact of access to daycare on labor force participation may be stronger among women who are not working or underemployed,(Angeles et al. 2014; Barros et al. 2013) we conducted pre-specified analyses to assess whether the impact of the intervention differed by baseline work status, measured by any work in the past seven days and working year round.

\section{Statistical analyses}

Intent-to-treat analyses

Our primary specification was an intent-to-treat (ITT) model with adjustment for stratification by block. For continuous outcomes (time on childcare and total income) we used a random effects linear model of the form: 


$$
y_{i j}=\alpha+\beta Z_{j}+\sum_{k=1}^{K} \gamma_{k} K_{k}+u_{j}+\varepsilon_{i j},
$$

where $y_{i j}$ is the outcome of interest for individual $i$ in cluster $j, Z_{j}$ is the main cluster-level treatment assignment variable ( 1 for intervention, 0 for control), $\gamma_{k}$ are coefficients for each of the $K$ blocks on which we stratified randomized treatment assignment, $u_{j}$ is a cluster-level random effect, and $\varepsilon_{i j}$ is an error term. The random effects model is commonly applied to account for between-cluster variation in the analysis of cluster randomized controlled trials.(Hayes and Moulton 2017) The coefficient $\beta$ and its $95 \%$ confidence interval is our primary parameter of interest.

Equation 1 above represents an unadjusted model, but in order to increase precision we included additional baseline covariates that are strong predictors of the outcome, specifically pre-treatment outcomes measured at baseline:

$$
y_{i j}=\alpha+\beta Z_{j}+\sum_{k=1}^{K} \gamma_{k} K_{k}+\delta C_{i j}+u_{j}+\varepsilon_{i j},
$$

where $C_{i j}$ is the value of outcome $y_{i j}$ at baseline. Including measures of the outcome at baseline can lead to meaningful increases in power, especially for outcomes that are weakly correlated over time.(Frison and Pocock 1992; McKenzie 2012)

In order to test whether the ITT estimates differed by block and baseline work status, we extended the generalized linear model specified with covariates above (Equation 2) to allow for heterogeneity in the impact of the treatment: 


$$
y_{i j}=\alpha+\beta Z_{j}+\sum_{k=1}^{K} \gamma_{k} K_{k}+\delta C_{i j}+\theta\left(Z_{j} \times C_{i j}\right)+u_{j}+\varepsilon_{i j}
$$

where $\theta$ on the product term between treatment assignment $\left(Z_{j}\right)$ and a specific covariate $C$ provides a test of whether the program's impact is homogenous across levels of $C$.

For binary outcomes (balwadi use, worked in the past 7 days, self-employed, works year round, paid cash for work, any time spent on paid work) we used random effects logistic regression and reported marginal effects on the absolute risk scale. To account for non-independence of errors among observations in the same hamlet we used cluster-robust variance estimators in all models.(Cameron and Miller 2015; Hayes and Moulton 2017)

In terms of statistical inference, we report ITT estimates with $95 \%$ confidence intervals. There is debate in the literature over whether corrections should be applied to account for multiple comparisons.(Streiner and Norman 2011; Rothman 1990) In Supplementary Figures 3 through 10, we report ITT estimates with both standard $95 \%$ confidence intervals and adjusted confidence intervals that account for multiple comparisons (80 total ITT estimates) using Šidák’s method for calculating a familywise error rate (FWER) adjusted critical value.(Šidák 1967) The trial was not adequately powered to provide precise estimates of treatment effects within sample sub-groups and we lacked strong priors on which sub-groups (i.e., blocks or categories of baseline employment status) would benefit most from the intervention, given the lack of prior research.(Harper, Austin, and Nandi 2017) Accordingly, results from stratified analyses should be considered exploratory and for the purposes of stimulating further research. 
Two-stage least squares instrumental variables analyses

Equation 2 above may be considered as the ITT or reduced form equation for the impact of random assignment to a balwadi on our outcomes. We also explored the impact of maternal use of a balwadi on our primary outcomes using two-stage least squares (2SLS) instrumental variables analysis. For these analyses the basic identifying assumptions are that: (1) random assignment to daycare only affects outcomes through its impact on the actual take-up and use of daycare and (2) treatment assignment is not correlated with unobserved factors that predict outcomes.(Angrist, Imbens, and Rubin 1996; Angrist and Krueger 2001) We assessed "relevance", specifically a firststage effect of randomized assignment on women's balwadi use, the F-statistic.

We estimated the first stage equation, which gives the impact of randomized treatment assignment on daycare use:

$$
D_{i j}=\alpha+\beta Z_{j}+\sum_{k=1}^{K} \gamma_{k} K_{k}+\delta C_{i j}
$$

where $D_{i j}$ represents whether or not the respondent reported any use of a balwadi and the other parameters are defined similarly as in Equation 2 above. We used the coefficients from Equation 4 to predict, for each observation, the probability $\hat{Z}_{i j}$ of using a balwadi, as well as the residual $\widehat{D}_{i j}=Z_{j}-\hat{Z}_{i j}$, which is then added to the second stage equation along with the actual treatment status for models with binary outcomes (Baiocchi et al., 2017):

$$
y_{i j}=\zeta+\beta Z_{j}+\eta \widehat{D}_{i j}+\sum_{k=1}^{K} \theta_{k} K_{k}+\lambda C_{i j}+\varepsilon_{i j}
$$


In Equation 5, $y_{i j}$ is the outcome of interest and $\widehat{D}_{i j}$ is the residual derived from Equation 4. For binary outcomes this approach is less biased than just including the predicted value of the treatment from the first stage.(Cai, Small, and Have 2011) We used cluster-robust standard errors in both equations and bootstrapping with 1000 replications to obtain standard errors for instrumental variable estimates.(Angrist and Pischke 2008; Angrist, Imbens, and Rubin 1996)

\section{RESULTS}

\section{Descriptive findings}

Table 1 shows summary data for individuals in treated and control areas. As expected, baseline characteristics were balanced between the treatment and control arms of the trial. Only one-quarter of women had ever attended school and nearly all were married at the time of the baseline interview. In terms of employment, $62 \%$ of women reported working in the past week, $37 \%$ were self-employed, and $8 \%$ worked year round. However, only $9 \%$ of respondents were paid in cash for their work in the past year and only $6 \%$ of women reported spending at least some time on paid work in the past 24 hours. One-half of households reported having a Below the Poverty Line card and the mean income received by the household over the past year was Rs. 53806, or USD 839 based on an average annual exchange rate of 64.11 INR to 1 USD in 2015. Women reported spending roughly two and one-half hours per day on childcare.

There was substantial heterogeneity in sociodemographic and employment characteristics across the five study blocks (Table 2). For example, 15\% of women reported any schooling in Kotda, compared to $43 \%$ in Kherwara. The proportion of women who worked in the past 7 days ranged 
from $51 \%$ in Girwa to $77 \%$ in Kotda. In Kherwara, $6 \%$ of women were paid cash for the work they did in the past year, compared to $18 \%$ in Badgaon. The probability of being self-employed ranged from a $9 \%$ in Jhadol to $50 \%$ in Kherwara. The total household income was over twice as high in Kherwara (Rs. 69745) than in Kotda (Rs. 33696).

\section{Intent-to-treat estimates for the impact of random assignment to a balwadi}

The ITT effects of the intervention on each of the primary outcomes are shown in Figures 2 through 9, with corresponding estimates provided in Supplementary Tables 1, 2, and 3. Each figure includes the overall effects, the effects by block, and the effects by baseline employment status (i.e. whether the respondent worked in the past week and whether they reported working year round), along with $95 \%$ confidence intervals.

As shown in Figure 2, treatment assignment increased the probability that a respondent used a Seva Mandir operated balwadi during the roughly two-year follow-up by $43.4(95 \% \mathrm{CI}=37.8,49.0)$ percentage points (52.3\% in treated hamlets compared to $8.9 \%$ in control hamlets). There was substantial heterogeneity in the impact on the uptake of daycare across blocks, ranging from a low of 35.4 percentage points in Kherwara $(95 \% \mathrm{CI}=24.1,46.7)$ to a high of 59.7 percentage points in Badgaon $(95 \% \mathrm{CI}=49.4,70.1)$. Providing access to a balwadi also reduced women's total (direct and indirect) time spent on childcare (Figure 3) by 16.9 minutes per day $(95 \% \mathrm{CI}=-9.7,43.5)$, although there was substantial variability in this estimate.

The intervention did not have a noticeable effect on whether respondents reported working in the past 7 days (Figure 4), being self-employed (Figure 5), or working year round (Figure 6), but 
appeared to have modest impacts on whether they worked for cash. In particular, treatment assignment increased the proportion of women who worked in the past 12 months who were paid in cash for their work (Figure 7) by 2.3 percentage points $(95 \% \mathrm{CI}=0.0,4.5)$ and the proportion of women who spent any time in the past 24 hours on paid work (Figure 8) by 2.6 percentage points $(95 \% \mathrm{CI}=0.9,4.4)$.

There was a general trend for those who worked year round at baseline to benefit more from the intervention, although stratum-specific estimates were relatively imprecise since few respondents reported working year round at baseline; with a few exceptions, we did not detect reliable statistical differences across strata. For example, among women who reported working year round at baseline, treatment assignment increased the proportions of women who were paid cash for their work and who spent any time in the past 24 hours on paid work by $7.7(95 \% \mathrm{CI}=-0.4,15.9)$ and $10.8(95 \% \mathrm{CI}=2.4,19.2)$ percentage points, respectively, compared to $1.8(95 \% \mathrm{CI}=-0.5,4.1)$ and $1.6(95 \% \mathrm{CI}=-0.2,3.4)$ percentage points for women who were not working year round at baseline. Household income was generally unaffected by the intervention (Figure 9). Estimates were of similar magnitude in analyses restricted to mothers with a child less than 5 years of age at baseline (Supplementary Table 4).

\section{Instrumental variable estimates for the impact of maternal use of a balwadi}

Table 3 shows estimates for the impact of maternal use of a balwadi on our outcomes. The intervention had a strong effect on maternal use of a balwadi, as reflected by the large F-statistics for the first-stage effect of randomized assignment on women's balwadi use. Because the instrumental variable estimate is approximately equal to the ITT estimate divided by the 
compliance rate (for continuous outcomes), these estimates have greater uncertainty compared to the ITT estimates. Balwadi use was estimated to increase the probability of working year round by $6.0(95 \% \mathrm{CI}=-0.2,13.2)$ percentage points, being paid in cash by $6.7(95 \% \mathrm{CI}=1.0,15.0)$ percentage points, and spending any time in the past 24 hours on paid work by $7.9(95 \% \mathrm{CI}=2.4,15.9)$ percentage points, and decrease the total time spent on care work by 43 (95\% CI: $-5.3,91.9$ ) minutes.

\section{DISCUSSION}

The intervention was designed to address a potential barrier to women's economic participation, specifically the lack of affordable childcare options. Providing access to an affordable, communitybased daycare program led $52 \%$ of mothers with an age-eligible child in rural parts of the Udaipur district of Rajasthan to use them in some capacity in the two years after they were established (compared to $9 \%$ of mothers in control areas); mothers in treated areas reported using the daycares for roughly 5 days per week and 6 hours per day, on average, suggesting that there was substantial unmet need for affordable childcare. A comparison of women's outcomes in treated and control village hamlets after the balwadis were established showed modest differences, including a reduction in time spent on childcare and an increase in the probability of working for cash. There were some differences in treatment effects across blocks and according to baseline characteristics, with the largest changes in economic outcomes observed among women employed year round prior to the intervention.

One of the primary questions that our evaluation aimed to answer was whether providing access to affordable daycare would encourage utilization. Before conducting our evaluation, focus group 
discussions with mothers residing in non-study area villages with access to a Seva Mandir operated balwadi suggested that they were satisfied with the overall operation and quality of services provided, including the nutrition and education components in particular, and did not have reservations about leaving their children with the trained staff of the balwadi. These qualitative findings were confirmed by our quantitative evaluation, which showed that providing access to a balwadi encouraged over one-half of women in treated areas to use them in the two years after they were established. We found that daycare access reduced time spent on childcare by about 17 minutes; among those who made use of a balwadi, the reduction was approximately 43 minutes.

A simple multivariable regression analysis exploring the correlates of balwadi use in treated villages suggested that the block of residence was the primary source of variation, with corresponding ITT effects of the intervention on uptake ranging from a low of $33 \%$ in Kherwara to a high of $60 \%$ in Badgaon, after adjusting for other baseline covariates. Additionally, mothers who were younger and had more children, on average, were more likely to make use of the balwadis. The overall positive response to the balwadi program could be particular to Seva Mandir's model of participatory development, which is based on building partnerships with communities; in the case of the balwadi program, this meant implementing the program only in areas that expressed demand through the Village Development Committee. Whether access to a comparable model of daycare would influence uptake in other Indian contexts is unclear.

Our second aim was to investigate how access to affordable daycare might influence women's lives, including unpaid care work and paid employment. A recent systematic review of the literature measuring the impact of daycare provision on social, economic, and health outcomes in 
low- and middle-income countries found that interventions to increase daycare access resulted in a relatively minor increase in women's labor force participation.(Harper, Austin, and Nandi 2017) We found that providing access to daycare increased the proportion of women who were paid in cash for their work by 2.3 percentage points, among those who had worked in the past 12 months, and the proportion of women who spent any time in the past 24 hours on paid work by 2.6 percentage points; these effects were small in magnitude in absolute terms, but represented relative increases of $26 \%$ and $47 \%$ compared to their respective means, given the low proportion of respondents engaged in paid work at baseline. Instrumental variable estimates suggested that balwadi use led to important increases in the probabilities of being paid in cash and spending any time in the past 24 hours on paid work.

We did not observe consistent evidence for a short-term impact of balwadi access on other labor market outcomes, including the probability of working in the past 7 days or year round, although there was some evidence for concentrated effects in certain blocks. For example, in the Badgaon block, where the uptake of the intervention was the greatest, access to a balwadi increased the probability of working in the past 7 days by $9.7(95 \%$ CI: $0.2,19.2)$ percentage points and working year round by $7.3(95 \% \mathrm{CI}=-6.0,20.6)$, although some of these effects were estimated with imprecision. Statistical tests of homogeneity in treatment effects across blocks did not suggest significant effect measure modification, with the exceptions of balwadi use and household income. Contrary to the findings from a systematic review,(Harper, Austin, and Nandi 2017) our results stratified by baseline employment status suggested that the positive impacts of the intervention on employment-related outcomes were more pronounced among mothers who reported working year round at baseline; however, this was a small sub-group and estimates were imprecise. 
Several factors could have contributed to the limited impact of the intervention on women's labor force participation. First, recent periods of economic growth in India have not markedly increased or diversified employment opportunities for rural women,(Srivastava and Srivastava 2010) which might limit the potential for interventions, like the provision of daycare, to facilitate work outside the home. The National Rural Employment Guarantee Programme (NREGA), which provides up to 100 days per year of unskilled labor for any eligible rural household member at the statutory minimum wage, has been characterized by substantial unmet need in the poorest states, although participation by women in NREGA was relatively high in Rajasthan.(Dutta et al. 2012) If the lack of employment opportunities lessens the potential impact of daycare interventions to facilitate women's labor force participation then supply-side interventions, such as job training or employment targeting programs, may be required.(Jensen 2012; Field, Jayachandran, and Pande 2010) For example, a randomized trial showed that targeting economic opportunities to young women aged 15 to 21 years in rural India can increase the probability that they work outside the home.(Jensen 2012) The government of India has recently launched the Pradhan Mantri Kaushal Vikas Yogana, which aims at providing skill training to young people. Whether similar interventions would translate into improved economic outcomes for our target population, where the lack of childcare options is an additional barrier, is unclear. Second, patriarchal norms about women's roles in the workforce might limit their perceptions of their employment opportunities, and their ability to work outside the home. In our sample, the majority of women at baseline reported controlling behaviors by their husband; the incidence of emotional and physical abuse in the past year was also common and reported by roughly one third of women. Interventions which 
challenge traditional norms regarding women's roles, including those that increase women's employment, may increase the incidence of domestic violence.(Krishnan et al. 2010)

There were limitations to our study. First, it is possible that children from control villages may have attended a balwadi in a neighboring village, which could have biased our estimates toward the null. To prevent this, we imposed a buffer around each hamlet. Moreover, hamlets in the region are typically dispersed and daily travel between hamlets is relatively rare. Nonetheless, based on our endline data, about $9 \%$ of mothers from control hamlets reported at least some balwadi use over the two-year follow-up. Second, substantial losses to follow-up could induce selection bias if they were correlated with our outcomes (e.g., women who began working were less likely to respond to the midline survey) and differential by treatment status. However, we were able to follow $90 \%$ of baseline respondents during the midline and endline surveys, which limited the potential for selection bias. Third, non-compliance and partial compliance could occur if hamlets assigned to the treatment arm did not open a daycare center, closed a daycare center before the end of the study period, or operated the balwadi for limited days and/or hours. For example, a balwadi closed in a treated hamlet if a government anganwadi were to open in the same hamlet, since Seva Mandir does not operate balwadis in hamlets with a government program. Additionally, a center might close or operate in a limited capacity if a sanchalika became unable to operate the center and a suitable replacement could not be identified. Non-compliance would tend to dilute treatment effects comparing respondents in treated and control hamlets. Based on camera monitoring data from Seva Mandir, the balwadis were open for more than two-thirds of the days they were scheduled to operate; across hamlets, there was a positive correlation between the proportion of days the balwadis were operational and the proportion of mothers who reported using them. 
Fourth, our instrumental variable analyses assume that daycare use is likely the principal pathway through which access to a balwadi would impact our primary outcomes relating to women's labor force participation. However, it is possible that balwadi access could have had spillover effects within the community that may have affected a respondent's employment opportunities irrespective of their balwadi use. For example, use of the balwadi by neighbors and kin could have positively impacted a respondent's ability to engage in paid work, even if they did not utilize the balwadi themselves, by providing childcare on an informal, as needed basis.

Caveats considered, our findings on the impacts of a population-level intervention that provided access to daycare to randomly selected village hamlets in the Udaipur District of Rajasthan suggests substantial unmet need for childcare services, and the potential for an affordable, community-based program to satisfy that demand. The intervention had a positive, but not transformative, impact on some economic outcomes, including the probability that women were engaged in work for cash. These modest effects on labor market outcomes suggest the presence of other structural barriers beyond the lack of affordable daycare. Given the lack of viable public options for daycare, many civil society organizations have implemented community-based daycare programs in rural and urban contexts, which introduces opportunities for further evaluation and knowledge synthesis.

\section{DECLARATIONS}

\section{Trial registration}

The trial is registered through: (1) the ISRCTN clinical trial registry (ISRCTN45369145), http://www.isrctn.com/ISRCTN45369145, registered on May 16, 2016 and (2) the American Economic Association's (AEA) registry for randomized controlled trials (AEARCTR-0000774), http://www.socialscienceregistry.org/trials/774, registered on July 15, 2015. A pre-analysis plan is included in the AEA registration of the trial.

\section{Ethics approval and consent to participate}


The Institutional Review Board of McGill University's Faculty of Medicine and the Human Subjects Committee of the Institute for Financial Management and Research in Chennai, India approved this study. Potential respondents were given the opportunity to refuse or consent to participation in the study. After describing the study objectives, procedures, potential risks, potential benefits, voluntary nature, confidentiality and privacy protections, and compensation, each eligible respondent was asked if they would consent to participate. This was done in written form for respondents who could read and write and orally for those who could not.

\section{Availability of data and material}

The data collected as part of this ongoing trial will be made available at the end of the study, after all data have been collected and cleaned.

\section{Competing interests}

The authors declare they have no competing interests.

\section{Funding}

This work was carried out with financial support from the UK Government's Department of International Development (DFID) and the International Development Research Centre (IDRC), Canada. The views expressed herein are those of the authors and do not necessarily reflect those of DFID or IDRC.

\section{REFERENCES}

Angeles, Gustavo, Paola Gadsden, Sebastian Galiani, Paul Gertler, Andrea Herrera, Patricia Kariger, and Enrique Seira. 2014. "The impact of daycare on maternal labour supply and child development in Mexico, 3ie Impact Evaluation Report 6." In. New Delhi, India: International Initiative for Impact Evaluation (3ie).

Angrist, Joshua D, Guido W Imbens, and Donald B Rubin. 1996. "Identification of causal effects using instrumental variables." Journal of the American statistical Association 91 (434):444-55.

Angrist, Joshua D, and Alan B Krueger. 2001. "Instrumental variables and the search for identification: From supply and demand to natural experiments." Journal of Economic Perspectives 15 (69-85). 
Angrist, Joshua D, and Jörn-Steffen Pischke. 2008. Mostly harmless econometrics: An empiricist's companion: Princeton university press.

Attanasio, Orazio, and Marcos Vera-Hernandez. 2004. "Medium- and long run effects of nutrition and child care: evaluation of a community nursery programme in rural Colombia, IFS report EWP04/06." In.: The Institue for Fiscal Studies.

Barros, Ricardo, Pedro Olinto, Trine Lunde, and Mirela Carvalho. 2013. "The impact of access to free childcare on women's labor market outcomes: evidence from a randomized trial in low-income neighborhoods of Rio de Janeiro." enGender Impact : the World Bank's Gender Impact Evaluation Database.

Beaman, Lori, Esther Duflo, Rohini Pande, and Petia Topalova. 2012. "Female leadership raises aspirations and educational attainment for girls: A policy experiment in India." science 335 (6068):582-6.

Berlinski, Samuel, Sebastian Galiani, and Paul Gertler. 2009. "The effect of pre-primary education on primary school performance." Journal of Public Economics 93 (1):219-34.

Berlinski, Samuel, Sebastian Galiani, and Patrick J McEwan. 2011. "Preschool and maternal labor market outcomes: evidence from a regression discontinuity design." Economic Development and Cultural Change 59 (2):313-44.

Brown, Taylor W, Felix C van Urk, Rebecca Waller, and Evan Mayo-Wilson. 2014. "Centre-based day care for children younger than five years of age in low-and middle-income countries." Cochrane Database of Systematic Reviews (9):Art. No.: CD010543.

Cai, Bing, Dylan S Small, and Thomas R Ten Have. 2011. "Two-stage instrumental variable methods for estimating the causal odds ratio: Analysis of bias." Statistics in medicine 30 (15):1809-24.

Cameron, A Colin, and Douglas L Miller. 2015. "A practitioner's guide to cluster-robust inference." Journal of human resources 50 (2):317-72.

Chatterjee, Patralekha. 2011. "India grapples with its child marriage challenge." The Lancet 378 (9808):1987-8.

Chaudhary, Ruchika, and Sher Verick. 2014. Female labour force participation in India and beyond, ILO Asia-Pacific working paper series. New Delhi: International Labour Organization.

Chudasama, Rajesh K, Umed V Patel, Amiruddin M Kadri, Arohi M Mitra, Dhara T Thakkar, and Jasmin O Oza. 2016. "Evaluation of integrated Child Development Services program in Gujarat, India for the years 2012 to 2015." Indian J Public Health 60 (2):124-30. doi: 10.4103/0019-557x.184544.

De, Anuradha, and PROBE Team (India). 2011. Probe revisited : a report on elementary education in India. New Delhi: Oxford University Press.

Deutsch, Ruthanne. 1998. "Does Child Care Pay? Labor Force Participation and Earnings: Effects on Access to Child Care in the Favelas of Rio de Janeiro."

Dutta, Puja, Rinku Murgai, Martin Ravallion, and Dominique P Van de Walle. 2012. "Does India's employment guarantee scheme guarantee employment?".

Field, Erica, Seema Jayachandran, and Rohini Pande. 2010. "Do traditional institutions constrain female entrepreneurship? A field experiment on business training in India." The American Economic Review 100 (2):125-9.

Frison, Lars, and Stuart J Pocock. 1992. "Repeated measures in clinical trials: analysis using mean summary statistics and its implications for design." Statistics in medicine 11 (13):1685-704.

Harper, Sam, Nichole Austin, and Arijit Nandi. 2017. "Daycare and women's health, social, and economic outcomes in low- and middle-income countries: Systematic review and evidence synthesis." GrOW Research Series GWP-2017-07.

Hayes, Richard J, and Lawrence H Moulton. 2017. Cluster randomised trials: Chapman and Hall/CRC. 
Jensen, Robert. 2012. "Do labor market opportunities affect young women's work and family decisions? Experimental evidence from India." The Quarterly Journal of Economics 127 (2):753-92.

Kabeer, Naila. 2012. Women's economic empowerment and inclusive growth: labour markets and enterprise development: UK DFID and IDRC. https://www.soas.ac.uk/cdpr/publications/papers/file80432.pdf.

Kabeer, Naila, Simeen Mahmud, and Sakiba Tasneem. 2011. Does paid work provide a pathway to women's empowerment? Empirical findings from Bangladesh: Institute of Development Studies. $\quad$ http://www.ids.ac.uk/idspublication/does-paid-work-provide-a-pathway-towomen-s-empowerment-empirical-findings-from-bangladesh.

Kapsos, Steven, Andrea Silbermann, and Evangelia Bourmpoula. 2014. "Why is female labour force participation declining so sharply in India? ILO Research Paper no. 10." In, edited by International Labour Office. Geneva, Switzerland: ILO.

Kishor, Sunita, and Kamla Gupta. 2009. "Gender Equality and Women's Empowerment in India. National Family Health Survey (NFHS-3), India, 2005-06." In. Calverton, Maryland.

Krishnan, Suneeta, Corinne H Rocca, Alan E Hubbard, Kalyani Subbiah, Jeffrey Edmeades, and Nancy S Padian. 2010. "Do changes in spousal employment status lead to domestic violence? Insights from a prospective study in Bangalore, India." Social Science \& Medicine 70 (1):136-43.

Malik, A., M. Bhilwar, N. Rustagi, and D. K. Taneja. 2015. "An assessment of facilities and services at Anganwadi centers under the Integrated Child Development Service scheme in Northeast District of Delhi, India." Int J Qual Health Care 27 (3):201-6. doi: 10.1093/intqhc/mzv028.

McKenzie, David. 2012. "Beyond baseline and follow-up: The case for more T in experiments." Journal of development Economics 99 (2):210-21.

Mullainathan, Sendhil, and Eldar Shafir. 2013. Scarcity: Why having too little means so much: Macmillan.

Nakahara, Shinji, Krishna C Poudel, Milan Lopchan, Om Raj Poudel, Kalpana Poudel-Tandukar, and Masao Ichikawa. 2010. "Differential effects of out-of-home day care in improving child nutrition and augmenting maternal income among those with and without childcare support: A prospective before-after comparison study in Pokhara, Nepal." Health Policy 97 (1):16-25.

Nandi, Arijit, Shannon Maloney, Parul Agarwal, Anoushaka Chandrashekar, and Sam Harper. 2016. "The effect of an affordable daycare program on health and economic well-being in Rajasthan, India: protocol for a cluster-randomized impact evaluation study." BMC public health $16(1): 490$.

Palriwala, Rajni, and N Neetha. 2011. "Stratified familialism: the care regime in India through the lens of childcare." Development and change 42 (4):1049-78.

Paul, Tanusree, and Saraswati Raju. 2014. "Gendered labour in India." Economic \& Political Weekly 49 (29):197.

"Performance of the Rajiv Gandhi National Crèche Scheme for Children of Working Mothers." In. 2013. New Delhi: Planning Commission, Government of India.

PROBE Team (India), and Delhi School of Economics. Centre for Development Economics. 1999. Public report on basic education in India. New Delhi: Oxford University Press.

Rothman, Kenneth J. 1990. "No adjustments are needed for multiple comparisons." Epidemiology:43-6.

Sahoo, Jyotiranjan, Preetam B Mahajan, Sourabh Paul, Vikas Bhatia, Abhinash K Patra, and Dilip K Hembram. 2016. "Operational Assessment of ICDS Scheme at Grass Root Level in a Rural Area of Eastern India: Time to Introspect." J Clin Diagn Res 10 (12):Lc28-Ic32. doi: $10.7860 / j c d r / 2016 / 23059.9041$. 
Sharma, Ruchita, Shubhangna Sharma, and Shipra Nagar. 2007. "Extent of Female School Drop outs in Kangra District of Himachal Pradesh." Journal of Social Science 15 (3):201-4.

Šidák, Zbyněk. 1967. "Rectangular confidence regions for the means of multivariate normal distributions." Journal of the American statistical Association 62 (318):626-33.

Sorsa, Piritta, Jan Mares, Mathilde Didier, Caio Guimaraes, Marie Rabate, Gen Tang, and Annamaria Tuske. 2015. "Determinants of the low female labour force participation in India." In.: OECD Economics Department Working Papers No. 1207.

Srivastava, Nisha, and Ravi Srivastava. 2010. "Women, work, and employment outcomes in rural India." Economic and Political Weekly:49-63.

"Steering Committee on Women's Agency and Child Rights. Twelfth Five Year Plan (2012-2017)." In. 2011. New Delhi: Planning Commission, Government of India.

Streiner, David L, and Geoffrey R Norman. 2011. "Correction for multiple testing: is there a resolution?" Chest 140 (1):16-8.

Subramanian, S. V., and G. D. Smith. 2006. "Patterns, distribution, and determinants of underand overnutrition: a population-based study of women in India." Am J Clin Nutr 84 (3):63340. doi: $84 / 3 / 633$ [pii].

Sundaram, Aparna, and Reeve Vanneman. 2008. "Gender differentials in literacy in India: The intriguing relationship with women's labor force participation." World Development 36 (1):128-43.

Verick, Sher. 2018. "The puzzles and contradictions of the Indian labour market: What will the future of work look like?".

Woetzel, Jonathan, Anu Madgavkar, Rajat Gupta, James Manyika, Kweilin Ellingrud, Shishir Gupta, and Mekala Krishnan. 2015. "The Power of Parity: Advancing Women's Equality in India." In. New Delhi, India: McKinsey Global Institute.

World Economic Forum. The global gender gap report 2016. 2016. Cologny/Geneva, Switzerland: World Economic Forum.

Wu, Kin Bing, Pete Goldschmidt, Christy Kim Boscardin, and Mehtabul Azam. 2007. "Girls in India: Poverty, location, and social disparities." Exclusion, gender and education: Case studies from the developing world:119-43. 
Table 1. Baseline characteristics for the total sample and stratified by treatment status

\begin{tabular}{|l|c|c|c|c|c|c|c|}
\hline & \multicolumn{2}{|c|}{ Total sample } & \multicolumn{2}{c|}{ Control } & \multicolumn{2}{c|}{ Treated } \\
\hline \hline Variable & No. & Mean & SD & Mean & SD & Mean & SD \\
\hline Age & 2856 & 30.0 & 6.8 & 30.1 & 6.7 & 30.0 & 6.8 \\
\hline Any schooling & 2857 & 25.6 & 43.6 & 26.2 & 44.0 & 24.9 & 43.3 \\
\hline Currently married & 2858 & 98.6 & 11.9 & 98.9 & 10.6 & 98.3 & 13.0 \\
\hline Age married & 2766 & 17.5 & 2.8 & 17.5 & 2.7 & 17.4 & 3.0 \\
\hline Any schooling (husband) & 2835 & 65.3 & 47.6 & 67.9 & 46.7 & 62.7 & 48.4 \\
\hline Below poverty line & 2849 & 50.4 & 50.0 & 51.5 & 50.0 & 49.3 & 50.0 \\
\hline Number of children & 2858 & 3.3 & 1.6 & 3.3 & 1.6 & 3.3 & 1.6 \\
\hline Hindu religion & 2857 & 71.8 & 45.0 & 72.0 & 44.9 & 71.6 & 45.1 \\
\hline Minutes on childcare (direct) & 2854 & 148.1 & 140.6 & 150.2 & 139.9 & 146.0 & 141.4 \\
\hline Worked in past 7 days & 2858 & 62.0 & 48.5 & 62.0 & 48.6 & 62.0 & 48.6 \\
\hline Self-employed & 2720 & 37.1 & 48.3 & 34.8 & 47.7 & 39.3 & 48.9 \\
\hline Works year round & 2720 & 8.1 & 27.3 & 8.9 & 28.5 & 7.4 & 26.2 \\
\hline Paid cash for work & 2720 & 9.0 & 28.6 & 9.5 & 29.4 & 8.5 & 27.9 \\
\hline Any time on paid work & 2855 & 5.5 & 22.8 & 5.4 & 22.7 & 5.6 & 22.9 \\
\hline Total income (Rs.) & 2857 & 53806 & 42575 & 54414 & 43694 & 53222 & 41479 \\
\hline
\end{tabular}

${ }^{1}$ Variables are: age in years (age); whether the respondent ever attended school (any schooling) or not; whether the respondent was married (currently married) or not married, including widowed, divorced, separated, or living together; the age at marriage, if married (age married); whether the respondent's husband ever attended school (any schooling (husband)); whether the household has a Below the Poverty Line card (below poverty line) or not; the number of children under age $18 \mathrm{y}$ who live at home (Number of children); Hindu religion (Hindu) or other, including other religion, no religion, or unknown; the time spent in the past day caring for young children (minutes on childcare (direct)); whether the respondent worked in the past seven days (worked in past 7 days) or not; whether respondents who reported working in the past 12 months were self-employed (self-employed) or not, including working for a family member, the government, or someone else; whether respondents who reported working in the past 12 months worked year round (works year round) or not, including seasonally/part of the year or once in a while; whether respondents who reported working in the past 12 months were paid in cash (paid cash for work) or not; whether the respondent reported spending any time in the past day on paid work (any time on paid work); total income received by the household over the past year in Rupees (total income (Rs.)) 
Table 2. Baseline characteristics stratified by block

\begin{tabular}{|c|c|c|c|c|c|c|c|c|c|c|c|c|c|c|c|}
\hline \multirow[b]{2}{*}{ Variable $^{1}$} & \multicolumn{3}{|c|}{ Badgaon } & \multicolumn{3}{|c|}{ Girwa } & \multicolumn{3}{|c|}{ Jhadol } & \multicolumn{3}{|c|}{ Kherwara } & \multicolumn{3}{|c|}{ Kotda } \\
\hline & No. & Mean & SD & No. & Mean & SD & No. & Mean & SD & No. & Mean & SD & No. & Mean & SD \\
\hline Age & 336 & 30.2 & 6.4 & 735 & 29.2 & 6.2 & 756 & 30.0 & 6.6 & 427 & 29.7 & 6.5 & 602 & 31.2 & 7.8 \\
\hline Any schooling & 337 & 23.4 & 42.4 & 735 & 21.2 & 40.9 & 756 & 29.0 & 45.4 & 427 & 42.9 & 49.5 & 602 & 15.4 & 36.2 \\
\hline Currently married & 337 & 97.9 & 14.3 & 735 & 99.2 & 9.0 & 756 & 99.1 & 9.6 & 428 & 98.4 & 12.7 & 602 & 97.7 & 15.1 \\
\hline Age at marriage & 316 & 17.4 & 3.0 & 701 & 17.3 & 2.6 & 745 & 17.7 & 2.6 & 427 & 17.6 & 3.1 & 577 & 17.2 & 3.1 \\
\hline Any schooling (husband) & 328 & 61.0 & 48.9 & 731 & 67.2 & 47.0 & 750 & 68.9 & 46.3 & 427 & 82.4 & 38.1 & 599 & 48.4 & 50.0 \\
\hline Below poverty line & 336 & 57.1 & 49.6 & 733 & 40.5 & 49.1 & 753 & 52.5 & 50.0 & 428 & 62.1 & 48.6 & 599 & 47.6 & 50.0 \\
\hline Number of children & 337 & 2.8 & 1.3 & 735 & 3.1 & 1.5 & 756 & 3.2 & 1.5 & 428 & 3.3 & 1.6 & 602 & 3.9 & 1.9 \\
\hline Hindu religion & 337 & 72.4 & 44.8 & 735 & 71.4 & 45.2 & 756 & 67.3 & 46.9 & 427 & 74.5 & 43.7 & 602 & 75.6 & 43.0 \\
\hline Minutes on childcare (direct) & 337 & 130.0 & 156.9 & 733 & 166.2 & 158.5 & 755 & 139.7 & 117.8 & 427 & 149.1 & 118.1 & 602 & 145.9 & 146.8 \\
\hline Worked in past 7 days & 337 & 54.3 & 49.9 & 735 & 50.7 & 50.0 & 756 & 61.4 & 48.7 & 428 & 67.8 & 46.8 & 602 & 76.7 & 42.3 \\
\hline Self employed & 310 & 35.8 & 48.0 & 690 & 54.6 & 49.8 & 721 & 8.9 & 28.5 & 420 & 50.0 & 50.1 & 579 & 42.8 & 49.5 \\
\hline Works year round & 310 & 9.0 & 28.7 & 690 & 8.4 & 27.8 & 721 & 6.8 & 25.2 & 420 & 6.2 & 24.1 & 579 & 10.4 & 30.5 \\
\hline Paid cash for work & 310 & 18.1 & 38.5 & 690 & 8.1 & 27.3 & 721 & 9.2 & 28.9 & 420 & 5.5 & 22.8 & 579 & 7.6 & 26.5 \\
\hline Any time on paid work & 337 & 8.9 & 28.5 & 734 & 6.3 & 24.3 & 755 & 5.3 & 22.4 & 427 & 4.2 & 20.1 & 602 & 3.8 & 19.2 \\
\hline Total income (Rs.) & 337 & 54129 & 43014 & 734 & 60771 & 41176 & 756 & 53890 & 41116 & 428 & 69745 & 53241 & 602 & 33696 & 26996 \\
\hline
\end{tabular}

${ }^{1}$ Variables are: age in years (age); whether the respondent ever attended school (any schooling) or not; whether the respondent was married (currently married) or not married, including widowed, divorced, separated, or living together; the age at marriage, if married (age married); whether the respondent's husband ever attended school (any schooling (husband)); whether the household has a Below the Poverty Line card (below poverty line) or not; the number of children under age 18 y who live at home (Number of children); Hindu religion (Hindu) or other, including other religion, no religion, or unknown; the time spent in the past day caring for young children (minutes on childcare (direct)); whether the respondent worked in the past seven days (worked in past 7 days) or not; whether respondents who reported working in the past 12 months were self-employed (self-employed) or not, including working for a family member, the government, or someone else; whether respondents who reported working in the past 12 months worked year round (works year round) or not, including seasonally/part of the year or once in a while; whether respondents who reported working in the past 12 months were paid in cash (paid cash for work) or not; whether the respondent reported spending any time in the past day on paid work (any time on paid work); total income received by the household over the past year in Rupees (total income (Rs.)) 
Table 3. The impact of any balwadi use on women's employment, time spent on childcare, and household income

\begin{tabular}{|l|c|c|c|c|c|}
\hline \multicolumn{1}{|c|}{ Variables $^{\mathbf{1}}$} & No. & Estimate $^{\mathbf{2}}$ & $\mathbf{9 5 \%}$ LCL & 95\% UCL & F-statistic \\
\hline \hline Any work in past 7 days & 2858 & 0.8 & -3.6 & 4.6 & 196.5 \\
\hline Self employed & 2702 & -0.9 & -9.5 & 7.6 & 186.3 \\
\hline Works year round & 2702 & 6.0 & -0.2 & 13.2 & 186.2 \\
\hline Paid in cash & 2702 & 6.7 & 1.0 & 15.0 & 186.4 \\
\hline Any time on paid work & 2855 & 7.9 & 2.4 & 15.9 & 195.8 \\
\hline Total minutes on childcare & 2853 & -43.3 & -91.9 & 5.3 & 195.9 \\
\hline Total income (Rs) & 2857 & -1380 & -10048 & 7177 & 197.5 \\
\hline
\end{tabular}

${ }^{1}$ Variables are: whether the respondent worked in the past seven days (worked in past 7 days) or not; whether respondents who reported working in the past 12 months were self-employed (self-employed) or not, including working for a family member, the government, or someone else; whether respondents who reported working in the past 12 months worked year round (works year round) or not, including seasonally/part of the year or once in a while; whether respondents who reported working in the past 12 months were paid in cash (paid cash for work) or not; whether the respondent reported spending any time in the past day on paid work (any time on paid work); the total time spent in the past day caring for young children, including direct and indirect childcare (total minutes on childcare); total income received by the household over the past year in Rupees (total income (Rs.))

${ }^{2}$ Estimates for minutes spent on childcare and total income are from two-stage least squares estimation with cluster robust standard errors. Estimates for the remaining binary outcomes are derived from a two-stage model. The first stage regressed maternal balwadi use on the randomized treatment indicator and block using cluster robust standard errors. In the second stage, the predicted probability of balwadi use from the first stage was used to estimate the impact of balwadi use on binary outcomes using logistic regression and marginal effects. Standard errors were calculated by bootstrapping this procedure 100 times. 
Supplementary Table 1. The impact of providing access to a balwadi on women's employment, time spent on childcare, and household income

\begin{tabular}{|l|c|c|c|c|c|c|c|c|}
\hline & \multicolumn{3}{|c|}{ Without baseline controls } & \multicolumn{3}{c|}{ Controls for baseline value } \\
\hline \hline Variables $^{1}$ & No. & Estimate & 95\% LCL & 95\% UCL & No. & Estimate & 95\% LCL 95\% UCL \\
\hline Balwadi use & 2858 & 43.4 & 37.8 & 49.0 & & & & \\
\hline Worked in past 7 days & 2858 & -0.4 & -4.0 & 3.3 & 2858 & -0.4 & -4.0 & 3.3 \\
\hline Self employed & 2840 & -0.5 & -5.0 & 4.0 & 2702 & -0.5 & -5.1 & 4.1 \\
\hline Works year round & 2840 & 2.1 & -1.1 & 5.2 & 2702 & 2.0 & -1.1 & 5.2 \\
\hline Paid in cash & 2840 & 2.0 & -0.3 & 4.2 & 2702 & 2.3 & 0.0 & 4.5 \\
\hline Any time on paid work & 2858 & 2.7 & 1.0 & 4.4 & 2855 & 2.6 & 0.9 & 4.4 \\
\hline Total minutes on childcare & 2857 & -16.9 & -43.5 & 9.7 & 2853 & -16.0 & -42.5 & 10.6 \\
\hline Total income (Rs.) & 2858 & -1074 & -5673 & 3525 & 2857 & -770 & -5180 & 3640 \\
\hline
\end{tabular}

${ }^{1}$ Variables are: whether the respondent utilized a Seva Mandir operated balwadi (balwadi use) or not; whether the respondent worked in the past seven days (worked in past 7 days) or not; whether respondents who reported working in the past 12 months were self-employed (self-employed) or not, including working for a family member, the government, or someone else; whether respondents who reported working in the past 12 months worked year round (works year round) or not, including seasonally/part of the year or once in a while; whether respondents who reported working in the past 12 months were paid in cash (paid cash for work) or not; whether the respondent reported spending any time in the past day on paid work (any time on paid work); the total time spent in the past day caring for young children, including direct and indirect childcare (total minutes on childcare); total income received by the household over the past year in Rupees (total income (Rs.))

${ }^{2}$ Note that the baseline control for the outcome, total minutes on childcare, was the number of minutes spent directly on childcare, since indirect time spent on childcare while performing other activities was not collected at baseline 
Supplementary Table 2. The impact of providing access to a balwadi on women's employment, time spent on childcare, and household income, stratified by block of residence

\begin{tabular}{|c|c|c|c|c|c|c|c|}
\hline & & Badgaon & Girwa & Jhadol & Kherwara & Kotda & \\
\hline Variable $^{1}$ & No. & Est $(95 \% C I)$ & Est $(95 \% C I)$ & Est $(95 \% C I)$ & Est $(95 \% \mathrm{CI})$ & Est $(95 \% C I)$ & p-value ${ }^{4}$ \\
\hline \multirow[t]{2}{*}{ Balwadi use } & & 59.7 & 47.1 & 44.6 & 35.4 & 33.4 & 0.01 \\
\hline & 2858 & $(49.4,70.1)$ & $(37.6,56.6)$ & $(33.5,55.8)$ & $(24.1,46.7)$ & $(16.9,49.9)$ & \\
\hline \multirow[t]{2}{*}{ Worked in past 7 days $^{2}$} & & 9.7 & -0.1 & -2.2 & -1.9 & -1.1 & 0.29 \\
\hline & 2858 & $(0.2,19.2)$ & $(-5.4,5.3)$ & $(-13.5,9.0)$ & $(-11.1,7.3)$ & $(-3.1,1.0)$ & \\
\hline \multirow[t]{2}{*}{ Self employed ${ }^{2}$} & & 1.1 & 0.8 & 0.1 & -0.1 & -4.2 & 0.95 \\
\hline & 2702 & $(-8.7,10.8)$ & $(-8.1,9.8)$ & $(-8.0,8.2)$ & $(-14.5,14.3)$ & $(-14.6,6.1)$ & \\
\hline \multirow[t]{2}{*}{ Works year round ${ }^{2}$} & & 7.3 & -0.5 & 0.6 & 5.2 & 1.7 & 0.49 \\
\hline & 2702 & $(-6.0,20.6)$ & $(-5.7,4.6)$ & $(-4.5,5.6)$ & $(0.3,10.1)$ & $(-8.2,11.7)$ & \\
\hline \multirow[t]{2}{*}{ Paid cash for work ${ }^{2}$} & & 6.9 & 0.9 & 4.2 & 2.9 & -1.5 & 0.34 \\
\hline & 2702 & $(-4.9,18.7)$ & $(-2.7,-4.6)$ & $(-0.3,8.1)$ & $(-1.2,7.0)$ & $(-6.2,3.2)$ & \\
\hline \multirow[t]{2}{*}{ Any time on paid work ${ }^{2}$} & & 3.1 & 1.5 & 4.3 & 2.7 & 1.4 & 0.55 \\
\hline & 2855 & $(-6.2,12.3)$ & $(-2.1,5.1)$ & $(1.5,7.1)$ & $(-1.7,7.1)$ & $(-0.3,3.2)$ & \\
\hline \multirow[t]{2}{*}{ Total minutes on childcare ${ }^{3}$} & & -37.2 & -9.8 & -46.6 & 4.0 & 18.3 & 0.33 \\
\hline & 2853 & $(-96.5,22.0)$ & $(-72.1,52.4)$ & $(-106.5,13.1)$ & $(-48.6,56.6)$ & $(-18.2,54.8)$ & \\
\hline \multirow[t]{2}{*}{ Total income (Rs.) ${ }^{2}$} & & -621 & -11140 & 6350 & -6890 & 6781 & 0.02 \\
\hline & 2857 & $(-9494,8253)$ & $(-21735,-544)$ & $(-1420,14120)$ & $(-16217,2436)$ & $(-1151,14713)$ & \\
\hline
\end{tabular}

Variables are: whether the respondent utilized a Seva Mandir operated balwadi (balwadi use) or not; whether the respondent worked in the past seven days (worked in past 7 days) or not; whether respondents who reported working in the past 12 months were self-employed (self-employed) or not, including working for a family member, the government, or someone else; whether respondents who reported working in the past 12 months worked year round (works year round) or not, including seasonally/part of the year or once in a while; whether respondents who reported working in the past 12 months were paid in cash (paid cash for work) or not; whether the respondent reported spending any time in the past day on paid work (any time on paid work); the total time spent in the past day caring for young children, including direct and indirect childcare (total minutes on childcare); total income received by the household over the past year in Rupees (total income (Rs.))

${ }^{2}$ Model controls for baseline values of the outcome

${ }^{3}$ Note that the baseline control for the outcome, total minutes on childcare, was the number of minutes spent directly on childcare, since indirect time spent on childcare while performing other activities was not collected at baseline

${ }^{4} \mathrm{P}$-value tests the equivalence of treatment effects across strata formed by geographic block of residence 
Supplementary Table 3. The impact of providing access to a balwadi on women's employment, time spent on childcare, and household income, stratified by baseline employment status

\begin{tabular}{|c|c|c|c|c|c|c|c|c|}
\hline & \multicolumn{4}{|c|}{ Worked in past 7 days } & \multicolumn{4}{|c|}{ Worked year round } \\
\hline & & No & Yes & & & No & Yes & \\
\hline Variable $^{1}$ & No. & Est $(95 \% C I)$ & Est $(95 \% C I)$ & p-value ${ }^{4}$ & No. & Est $(95 \% C I)$ & Est $(95 \% C I)$ & p-value $^{4}$ \\
\hline Balwadi use & 2858 & $\begin{array}{c}48.7 \\
(42.0,55.5)\end{array}$ & $\begin{array}{c}40.1 \\
(34.0,46.1)\end{array}$ & $<0.01$ & 2720 & $\begin{array}{c}43.4 \\
(37.7,49.1)\end{array}$ & $\begin{array}{c}40.7 \\
(28.4,52.9)\end{array}$ & 0.64 \\
\hline Worked in past 7 days $^{2}$ & 2858 & $\begin{array}{c}1.1 \\
(-3.6,5.7)\end{array}$ & $\begin{array}{c}-1.2 \\
(-4.8,2.4)\end{array}$ & 0.21 & 2720 & $\begin{array}{c}-0.7 \\
(-4.5,3.2)\end{array}$ & $\begin{array}{c}3.6 \\
(-1.5,8.7)\end{array}$ & 0.08 \\
\hline Self employed ${ }^{2}$ & 2702 & $\begin{array}{c}3.6 \\
(-3.8,10.9)\end{array}$ & $\begin{array}{c}-2.8 \\
(-8.0,2.5)\end{array}$ & 0.13 & 2702 & $\begin{array}{c}0.3 \\
(-4.5,5.2)\end{array}$ & $\begin{array}{c}-10.3 \\
(-24.2,3.6)\end{array}$ & 0.16 \\
\hline Works year round ${ }^{2}$ & 2702 & $\begin{array}{c}3.4 \\
(-0.9,7.7)\end{array}$ & $\begin{array}{c}1.5 \\
(-2.3,5.2)\end{array}$ & 0.44 & 2702 & $\begin{array}{c}1.7 \\
(-1.5,4.9)\end{array}$ & $\begin{array}{c}5.5 \\
(-4.6,15.6)\end{array}$ & 0.46 \\
\hline Paid cash for work ${ }^{2}$ & 2702 & $\begin{array}{c}2.8 \\
(-0.2,5.7)\end{array}$ & $\begin{array}{c}2.0 \\
(-0.8,4.8)\end{array}$ & 0.70 & 2702 & $\begin{array}{c}1.8 \\
(-0.5,4.1)\end{array}$ & $\begin{array}{c}7.7 \\
(-0.4,15.9)\end{array}$ & 0.15 \\
\hline Any time on paid work ${ }^{2}$ & 2855 & $\begin{array}{c}5.0 \\
(2.1,7.9)\end{array}$ & $\begin{array}{c}1.2 \\
(-0.9,3.2)\end{array}$ & 0.02 & 2717 & $\begin{array}{c}1.6 \\
(-0.2,3.4)\end{array}$ & $\begin{array}{c}10.8 \\
(2.4,19.2)\end{array}$ & 0.04 \\
\hline Total minutes on childcare ${ }^{3}$ & 2853 & $\begin{array}{c}-15.9 \\
(-55.1,23.3)\end{array}$ & $\begin{array}{c}-16.1 \\
(-46.6,14.4)\end{array}$ & 0.99 & 2715 & $\begin{array}{c}-15.3 \\
(-41.8,11.3)\end{array}$ & $\begin{array}{c}32.5 \\
(-33.1,98.1)\end{array}$ & 0.15 \\
\hline Total income (Rs.) ${ }^{2}$ & 2857 & $\begin{array}{c}-216 \\
(-6821,6389)\end{array}$ & $\begin{array}{c}-1117 \\
(-6851,4617)\end{array}$ & 0.84 & 2719 & $\begin{array}{c}-1233 \\
(-5757,3291)\end{array}$ & $\begin{array}{c}8194 \\
(-5090,21477) \\
\end{array}$ & 0.16 \\
\hline
\end{tabular}

1 Variables are: whether the respondent utilized a Seva Mandir operated balwadi (balwadi use) or not; whether the respondent worked in the past seven days (worked in past 7 days) or not; whether respondents who reported working in the past 12 months were self-employed (self-employed) or not, including working for a family member, the government, or someone else; whether respondents who reported working in the past 12 months worked year round (works year round) or not, including seasonally/part of the year or once in a while; whether respondents who reported working in the past 12 months were paid in cash (paid cash for work) or not; whether the respondent reported spending any time in the past day on paid work (any time on paid work); the total time spent in the past day caring for young children, including direct and indirect childcare (total minutes on childcare); total income received by the household over the past year in Rupees (total income (Rs.))

${ }^{2}$ Model controls for baseline values of the outcome

${ }^{3}$ Note that the baseline control for the outcome, total minutes on childcare, was the number of minutes spent directly on childcare, since indirect time spent on childcare while performing other activities was not collected at baseline

${ }^{4} \mathrm{P}$-value tests the equivalence of treatment effects across strata of baseline employment status 
Supplementary Table 4. The impact of providing access to a balwadi on women's employment, time spent on childcare, and household income, restricted to mothers with a child less than 5 years of age at baseline

\begin{tabular}{|c|c|c|c|c|}
\hline Variables $^{1}$ & No. & Estimate & $95 \%$ LCL & $95 \%$ UCL \\
\hline Balwadi use & 2619 & 45.3 & 39.5 & 51.1 \\
\hline Any work in past 7 days & 2619 & -0.2 & -3.8 & 3.3 \\
\hline Self employed & 2474 & -0.9 & -5.8 & 4.0 \\
\hline Works year round & 2474 & 1.3 & -2.0 & 4.5 \\
\hline Paid in cash & 2474 & 2.3 & 0.1 & 4.5 \\
\hline Any time on paid work & 2616 & 2.3 & 0.6 & 4.1 \\
\hline Minutes spent on childcare ${ }^{2}$ & 2615 & -21.6 & -48.4 & 5.2 \\
\hline Total household income (Rs) & 2618 & -4 & -4591 & 4583 \\
\hline
\end{tabular}

${ }^{1}$ Variables are: whether the respondent utilized a Seva Mandir operated balwadi (balwadi use) or not; whether the respondent worked in the past seven days (worked in past 7 days) or not; whether respondents who reported working in the past 12 months were self-employed (self-employed) or not, including working for a family member, the government, or someone else; whether respondents who reported working in the past 12 months worked year round (works year round) or not, including seasonally/part of the year or once in a while; whether respondents who reported working in the past 12 months were paid in cash (paid cash for work) or not; whether the respondent reported spending any time in the past day on paid work (any time on paid work); the total time spent in the past day caring for young children, including direct and indirect childcare (total minutes on childcare); total income received by the household over the past year in Rupees (total income (Rs.))

${ }^{2}$ Note that the baseline control for the outcome, total minutes on childcare, was the number of minutes spent directly on childcare, since indirect time spent on childcare while performing other activities was not collected at baseline 


\section{LIST OF FIGURES}

Figure 1. Participant flow diagram

Figure 2. Intent-to-treat effects of randomized balwadi access on balwadi use

Notes: Bars show 95\% confidence intervals; estimates include overall effect, effects by block, and effects by baseline working status

Figure 3. Intent-to-treat effects of randomized balwadi access on minutes spent on childcare Notes: Bars show 95\% confidence intervals; estimates include overall effect, effects by block, and effects by baseline working status

Figure 4. Intent-to-treat effects of randomized balwadi access on working in the past 7 days Notes: Bars show 95\% confidence intervals; estimates include overall effect, effects by block, and effects by baseline working status

Figure 5. Intent-to-treat effects of randomized balwadi access on being self employed Notes: Bars show 95\% confidence intervals; estimates include overall effect, effects by block, and effects by baseline working status

Figure 6. Intent-to-treat effects of randomized balwadi access on working year round Notes: Bars show 95\% confidence intervals; estimates include overall effect, effects by block, and effects by baseline working status

Figure 7. Intent-to-treat effects of randomized balwadi access on being paid in cash

Notes: Bars show 95\% confidence intervals; estimates include overall effect, effects by block, and effects by baseline working status

Figure 8. Intent-to-treat effects of randomized balwadi access on spending any time on paid work Notes: Bars show 95\% confidence intervals; estimates include overall effect, effects by block, and effects by baseline working status

Figure 9. Intent-to-treat effects of randomized balwadi access on total household income (Rupees) Notes: Bars show 95\% confidence intervals; estimates include overall effect, effects by block, and effects by baseline working status

Supplementary Figure 1. Conceptual model

Supplementary Figure 2. Location of study hamlets in Udaipur district, Rajasthan, India

Supplementary Figure 3. Intent-to-treat effects of randomized balwadi access on balwadi use Notes: Bars show standard 95\% confidence intervals and adjusted confidence intervals that account for multiple comparisons using Šidák's method; estimates include overall effect, effects by block, and effects by baseline working status 
Supplementary Figure 4. Intent-to-treat effects of randomized balwadi access on minutes spent on childcare Notes: Bars show standard 95\% confidence intervals and adjusted confidence intervals that account for multiple comparisons using Šidák's method; estimates include overall effect, effects by block, and effects by baseline working status

Supplementary Figure 5. Intent-to-treat effects of randomized balwadi access on working in the past 7 days Notes: Bars show standard 95\% confidence intervals and adjusted confidence intervals that account for multiple comparisons using Šidák's method; estimates include overall effect, effects by block, and effects by baseline working status

Supplementary Figure 6. Intent-to-treat effects of randomized balwadi access on being self employed Notes: Bars show standard 95\% confidence intervals and adjusted confidence intervals that account for multiple comparisons using Šidák's method; estimates include overall effect, effects by block, and effects by baseline working status

Supplementary Figure 7. Intent-to-treat effects of randomized balwadi access on working year round Notes: Bars show standard 95\% confidence intervals and adjusted confidence intervals that account for multiple comparisons using Šidák's method; estimates include overall effect, effects by block, and effects by baseline working status

Supplementary Figure 8. Intent-to-treat effects of randomized balwadi access on being paid in cash Notes: Bars show standard 95\% confidence intervals and adjusted confidence intervals that account for multiple comparisons using Šidák's method; estimates include overall effect, effects by block, and effects by baseline working status

Supplementary Figure 9. Intent-to-treat effects of randomized balwadi access on spending any time on paid work

Notes: Bars show standard 95\% confidence intervals and adjusted confidence intervals that account for multiple comparisons using Šidák's method; estimates include overall effect, effects by block, and effects by baseline working status

Supplementary Figure 10. Intent-to-treat effects of randomized balwadi access on total household income (Rupees)

Notes: Bars show standard 95\% confidence intervals and adjusted confidence intervals that account for multiple comparisons using Šidák's method; estimates include overall effect, effects by block, and effects by baseline working status 
Identify eligible clusters (village hamlets): 160 clusters were selected that satisfied five criteria determined a priori: (1) minimum distance $(>1.5 \mathrm{~km})$ between clusters, $(2)$ minimum number $(\geq 25)$ of age-eligible children; (3) presence of a suitable structure; (4) availability of a qualified woman to operate the daycare; and (5) adequate community demand.

\section{$\downarrow$}

Identify eligible households and respondents: Household census in 160 clusters to confirm eligibility, enumerate the population, and identify eligible households. From each eligible household we randomly selected of one mother (biological or guardian) of a child 1-6 years of age, resulting in $n=3899$ potential respondents.

\section{$\downarrow$}

Baseline survey: Baseline survey conducted in 160 clusters $(n=3899)$ in early 2015.

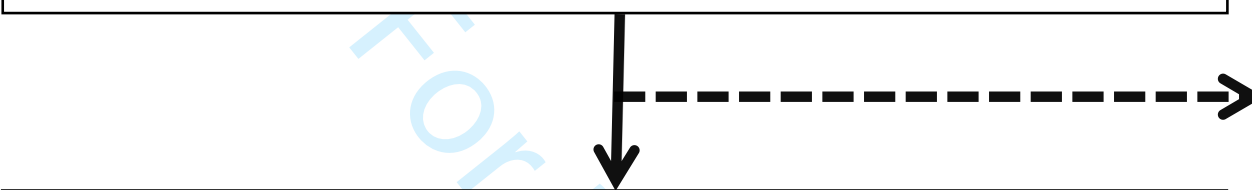

Baseline sample: $\mathrm{n}=3177$ participants from 160 clusters.

\section{Excluded:}

- 343 women were ineligible.

- 95 migrated from the study area.

- 127 could not be contacted after 3 visit attempts.

- 157 refused or did not respond for other reasons.

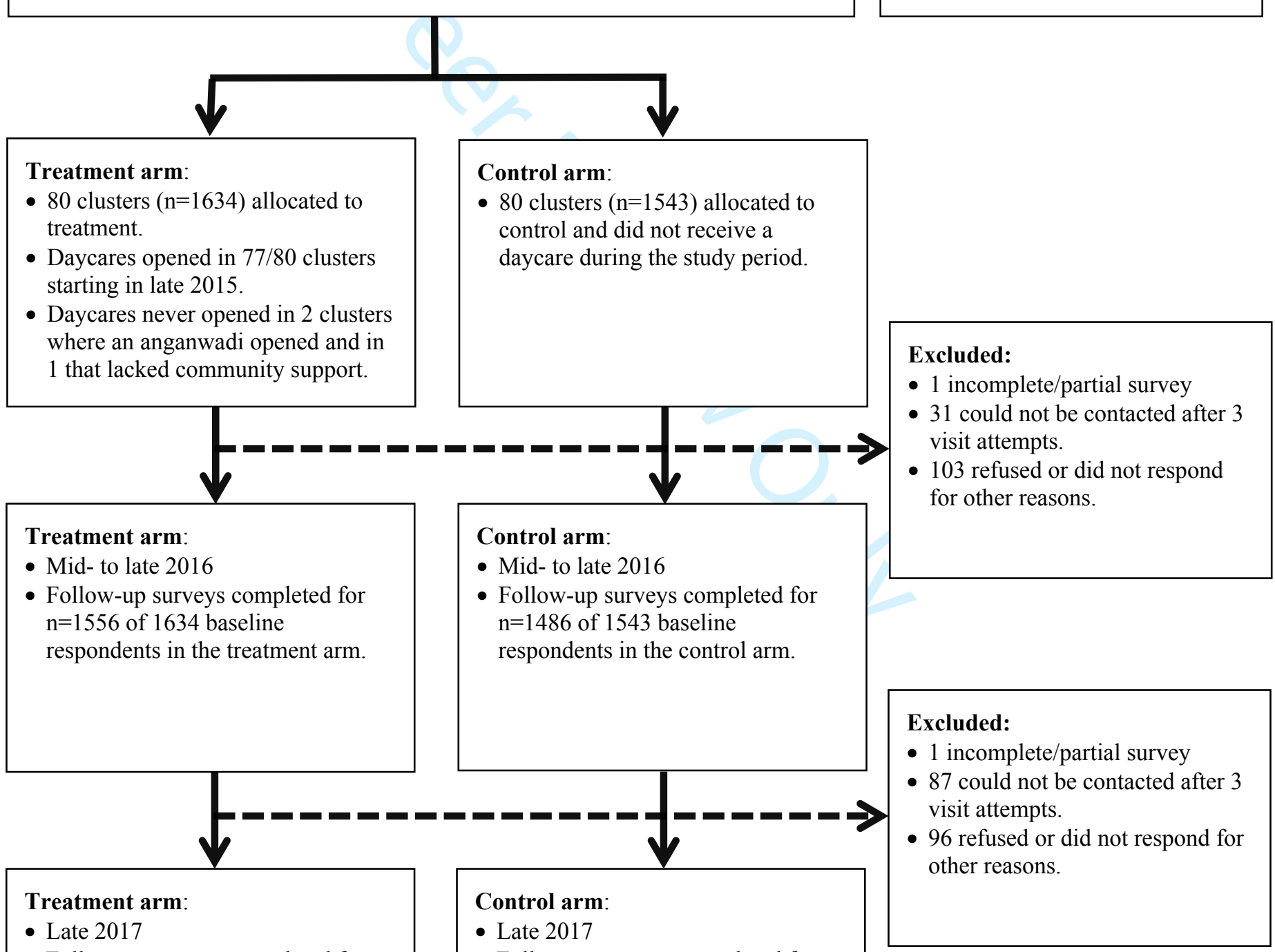

- Follow-up surveys completed for $\mathrm{n}=1458$ of 1634 baseline respondents in the treatment arm.

- Follow-up rate $=89.2 \%$

- Follow-up surveys completed for $\mathrm{n}=1401$ of 1543 baseline respondents in the control arm.

- Follow-up rate $=90.8 \%$. 
Figure 2. Intent-to-treat effects of randomized balwadi access on balwadi use Notes: Bars show 95\% confidence intervals; estimates include overall effect, effects by block, and effects by baseline working status 
Figure 3. Intent-to-treat effects of randomized balwadi access on minutes spent on childcareNotes: Bars show 95\% confidence intervals; estimates include overall effect, effects by block, and effects by baseline working status 


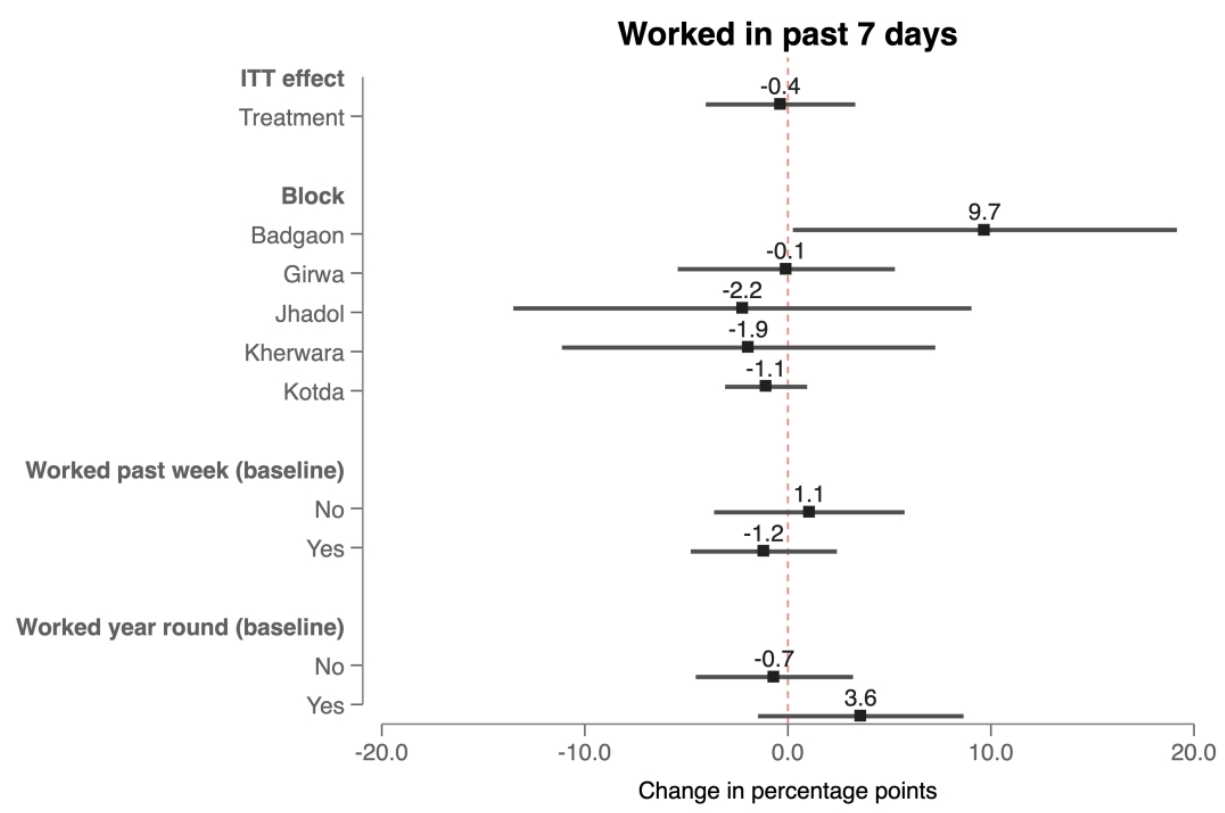

Figure 4. Intent-to-treat effects of randomized balwadi access on working in the past 7 daysNotes: Bars show 95\% confidence intervals; estimates include overall effect, effects by block, and effects by baseline working status 
Figure 5. Intent-to-treat effects of randomized balwadi access on being self employedNotes: Bars show $95 \%$ confidence intervals; estimates include overall effect, effects by block, and effects by baseline working status 


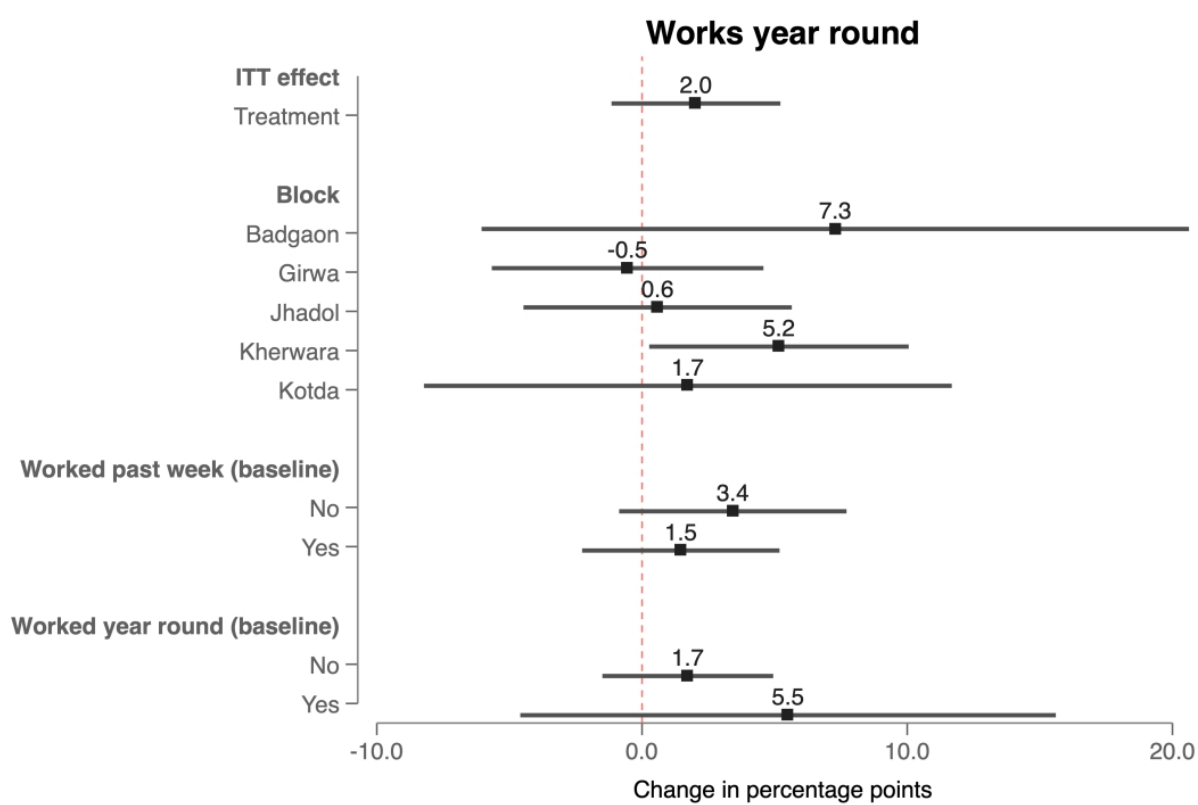

Figure 6. Intent-to-treat effects of randomized balwadi access on working year roundNotes: Bars show $95 \%$ confidence intervals; estimates include overall effect, effects by block, and effects by baseline working status 
Figure 7. Intent-to-treat effects of randomized balwadi access on being paid in cash Notes: Bars show $95 \%$ confidence intervals; estimates include overall effect, effects by block, and effects by baseline working status 
Figure 8. Intent-to-treat effects of randomized balwadi access on spending any time on paid workNotes: Bars show 95\% confidence intervals; estimates include overall effect, effects by block, and effects by baseline working status 
Figure 9. Intent-to-treat effects of randomized balwadi access on total household income (Rupees)Notes: Bars show 95\% confidence intervals; estimates include overall effect, effects by block, and effects by baseline working status 


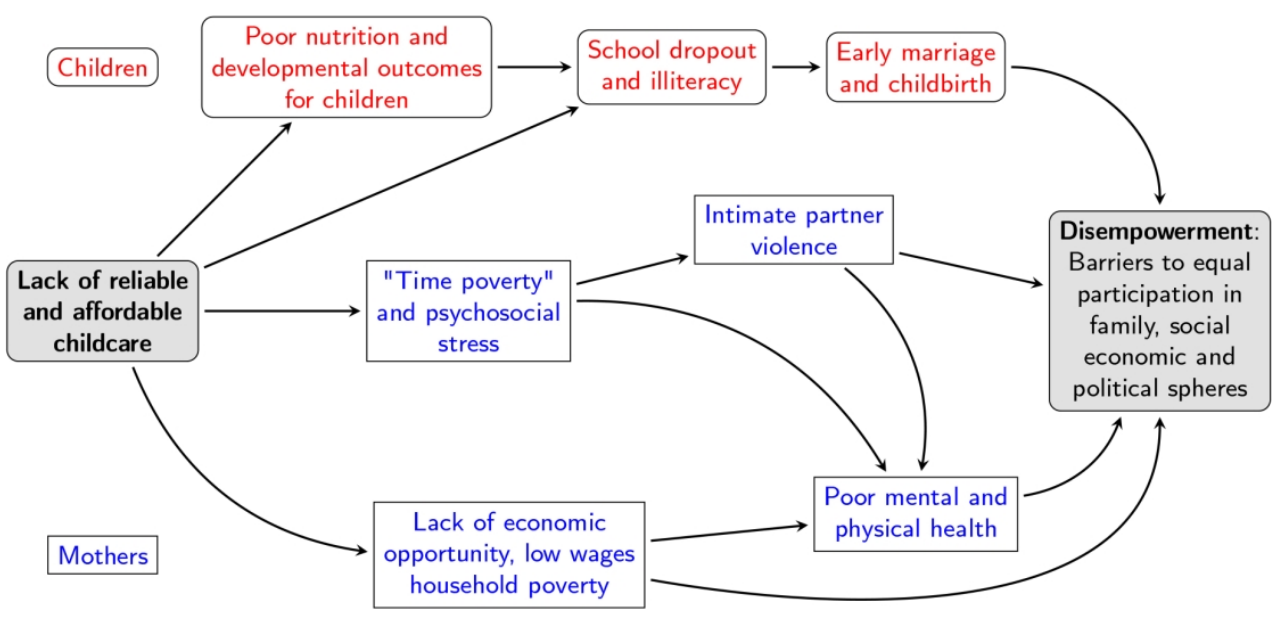

Overarching gender, socioeconomic environment, caste structures

Supplementary Figure 1. Conceptual model 


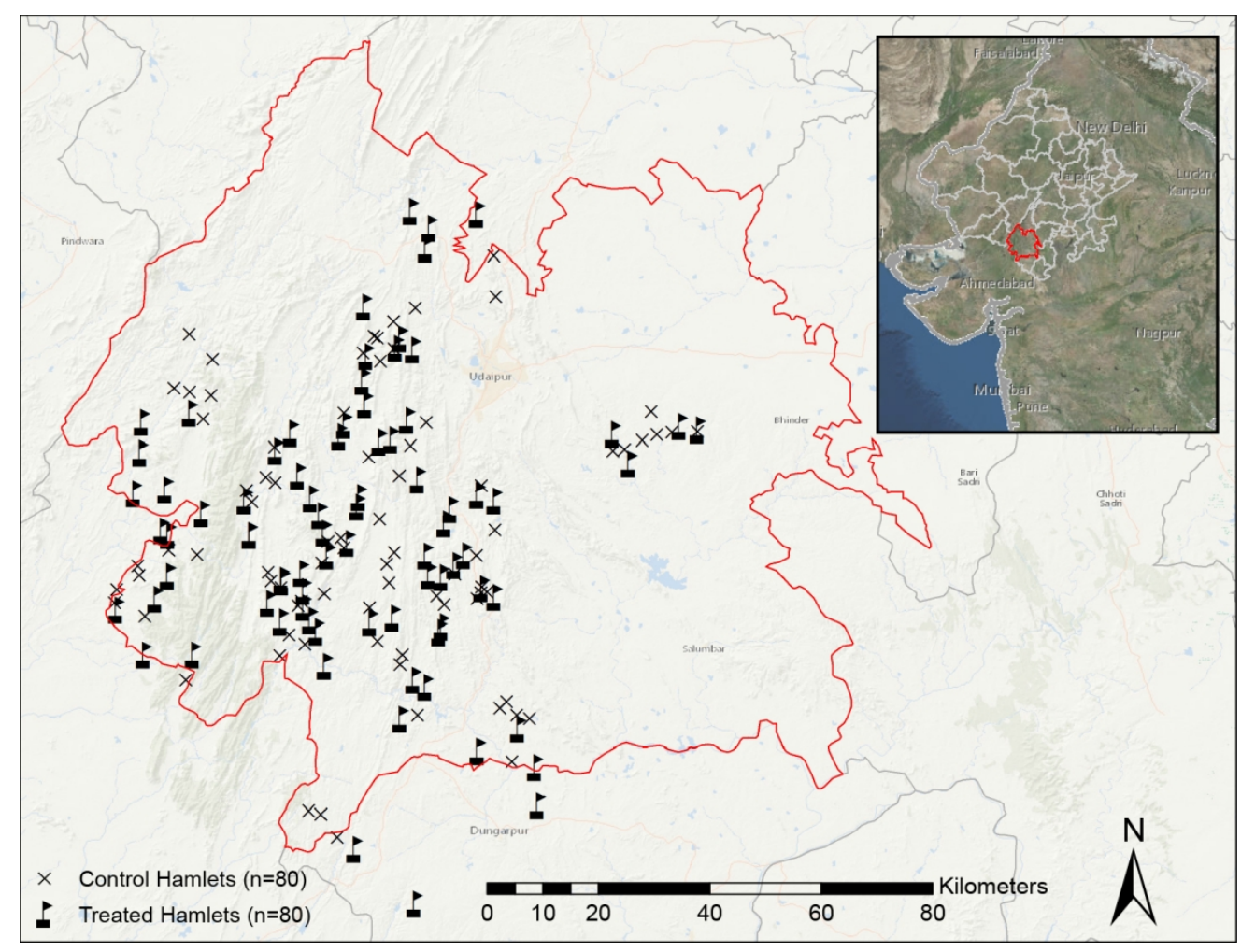

Supplementary Figure 2. Location of study hamlets in Udaipur district, Rajasthan, India 
Supplementary Figure 3. Intent-to-treat effects of randomized balwadi access on balwadi use Notes: Bars show standard 95\% confidence intervals and adjusted confidence intervals that account for multiple comparisons using Šidák's method; estimates include overall effect, effects by block, and effects by baseline working status 
Supplementary Figure 4. Intent-to-treat effects of randomized balwadi access on minutes spent on childcare Notes: Bars show standard 95\% confidence intervals and adjusted confidence intervals that account for multiple comparisons using Šidák's method; estimates include overall effect, effects by block, and effects by baseline working status 
Supplementary Figure 5. Intent-to-treat effects of randomized balwadi access on working in the past 7 days Notes: Bars show standard 95\% confidence intervals and adjusted confidence intervals that account for multiple comparisons using Šidák's method; estimates include overall effect, effects by block, and effects by baseline working status 
Supplementary Figure 6. Intent-to-treat effects of randomized balwadi access on being self employed Notes: Bars show standard 95\% confidence intervals and adjusted confidence intervals that account for multiple comparisons using Šidák's method; estimates include overall effect, effects by block, and effects by baseline working status 
Supplementary Figure 7. Intent-to-treat effects of randomized balwadi access on working year round Notes: Bars show standard 95\% confidence intervals and adjusted confidence intervals that account for multiple comparisons using Šidák's method; estimates include overall effect, effects by block, and effects by baseline working status 
Supplementary Figure 8. Intent-to-treat effects of randomized balwadi access on being paid in cash Notes: Bars show standard 95\% confidence intervals and adjusted confidence intervals that account for multiple comparisons using Šidák's method; estimates include overall effect, effects by block, and effects by baseline working status 
Supplementary Figure 9. Intent-to-treat effects of randomized balwadi access on spending any time on paid work

Notes: Bars show standard 95\% confidence intervals and adjusted confidence intervals that account for multiple comparisons using Šidák's method; estimates include overall effect, effects by block, and effects by baseline working status 
Supplementary Figure 10. Intent-to-treat effects of randomized balwadi access on total household income (Rupees)

Notes: Bars show standard 95\% confidence intervals and adjusted confidence intervals that account for multiple comparisons using Šidák's method; estimates include overall effect, effects by block, and effects by baseline working status 